\title{
Aspectos clínicos e epidemiológicos da infecção genital pelo papilomavírus humano em gestantes do município de Imperatriz, estado do Maranhão, Brasil
}

\section{Clinical and epidemiological aspects of human papillomavirus genital infection in pregnant women from Imperatriz, Maranhão State, Brazil}

Graciene Pereira de Sousa', Esther Iris Christina Freifrau von Ledebur², Marizeli Viana de Aragão Araújo ${ }^{3}$, George Alberto da Silva Dias ${ }^{4}$, Elcimara da Paixão Ferreira Chagas', Juarez Antônio Simões Quaresma ${ }^{4}$, Hellen Thaís Fuzii ${ }^{1}$

' Universidade Federal do Pará, Núcleo de Medicina Tropical, Laboratório de Imunopatologia, Belém, Pará, Brasil

2 Universidade Federal do Pará, Instituto de Ciências Biológicas, Belém, Pará, Brasil

${ }^{3}$ Universidade Federal do Pará, Instituto de Ciências da Saúde, Belém, Pará, Brasil

${ }^{4}$ Universidade do Estado do Pará, Centro de Ciências Biológicas e da Saúde, Belém, Pará, Brasil

\begin{abstract}
RESUMO
OBJETIVO: Determinar a prevalência da infecção da cérvice uterina pelo papilomavírus humano (HPV) em mulheres grávidas no município de Imperatriz, estado do Maranhão, Brasil. MATERIAIS E MÉTODOS: $O$ DNA-HPV foi detectado por reação em cadeia da polimerase em amostras de material cervicovaginal, coletadas com escova cervical, de 167 gestantes que responderam a um questionário com dados sociodemográficos, comportamentais e reprodutivos. RESULTADOS: A prevalência da infecção genital pelo HPV foi de 17,36\%. As gestantes solteiras/separadas/viúvas apresentaram quatro vezes mais chances de adquirir infecção pelo HPV que as casadas $(O R=4,03 ; p=0,0046)$. Primigestas apresentaram maior prevalência de infecção $(29,03 \%)$, sendo estatisticamente significantes (OR $=3,42 ; p=0,001)$. CONCLUSÃO: Os resultados permitem concluir que as gestantes mais suscetíveis à infecção pelo HPV são mulheres jovens, grávidas pela primeira vez e que estão em relações não estáveis, o que evidencia a necessidade de se combater a infecção por HPV pela implantação, ou ampliação de programas de educação sexual e planejamento familiar voltados para o público jovem, além de ampliar os programas continuados de vacinação contra o HPV.
\end{abstract}

Palavras-chave: Papilomavírus Humano; Gestação; Fatores de Risco.

\begin{abstract}
OBJECTIVE: To determine the prevalence of cervical human papillomavirus (HPV) infection in pregnant women from the Municipality of Imperatriz, Maranhão State, Brazil. MATERIALS AND METHODS: HPV-DNA was detected by polymerase chain reaction from cervicovaginal material collected with cervical brush from 167 pregnant women who answered a questionnaire with sociodemographic, behavioral and reproductive data. RESULTS: HPV genital infection prevalence was $17.36 \%$. Single pregnant women had four times higher chances of HPV infection than married pregnant women $(O R=4.03 ; p=0.0046)$. Primigravidas had higher infection prevalence $(29.03 \%)$, statistically significant $(O R=3.42 ; p=0.001)$. CONCLUSION: With these results it is possible to conclude that pregnant women who are more susceptible to HPV infection are young women, pregnant for the first time, and in unstable marital relationships, which shows the need to combat HPV infection by implanting or expanding sexual education and family planning programs focused on young people, in addition to expanding the continued anti-HPV vaccination programs.
\end{abstract}

Keywords: Human Papillomavirus; Pregnancy; Risk Factors.

\footnotetext{
Correspondência / Correspondence:

Hellen Thaís Fuzii

Núcleo de Medicina Tropical, Laboratório de Imunopatologia

Av. Generalíssimo Deodoro, 92. Bairro: Umarizal. CEP: 66055-240 - Belém, Pará, Brasil - Tel.: +55 (91) $3201-0954$

E-mail: hellen@ufpa.br
} 


\section{INTRODUÇÃO}

O câncer de colo uterino (CCU) é o quarto mais comum no mundo. Mais de 250.000 mulheres morrem por ano em consequência desse câncer, sendo que a maioria dessas mortes ocorre em países em desenvolvimento'. As estimativas do Instituto Nacional do Câncer (INCA) para 2018-2019 indicam mais de 16.000 novos casos de CCU a cada 100.000 mulheres no Brasil. Esse tipo de doença, com exceção dos casos de câncer de pele não melanoma, ocupa o terceiro lugar em incidência em mulheres brasileiras, estando atrás apenas dos cânceres de mama, cólon e reto e sendo a quarta causa de morte por câncer nessa população $o^{2,3}$.

A infecção pelo papilomavírus humano (HPV) é fator prioritário, mas não exclusivo para a ocorrência de CCU. $O$ material genético do HPV apresenta-se de 90 a $99 \%$ nas lesões precursoras CCU e nos tumores malignos. Um dado preocupante é a alta prevalência de infecção por HPV (15-40\%) em mulheres assintomáticas, uma vez que, ao não conseguir eliminar a infecção por HPV, são candidatas em potencial ao desenvolvimento de câncer se forem expostas a fatores de risco ${ }^{4,5}$

O HPV é um vírus de DNA, no qual há uma notável especificidade, induzindo lesões hiperplásicas, papilomatosas, verrucosas e lesões escamosas epiteliais na pele e em vários locais da mucosa, incluindo trato anogenital, uretra, laringe, as mucosas traqueobronqueal e nasal e a cavidade oral $^{6}$.

Os tipos de HPV são classificados como: 15 de alto risco oncogênico $(16,18,31,33,35,39,45,51,52$, 56, 58, 59, 68, 73 e 82); três de provável alto risco (26, 53 e 66); e 12 de baixo risco $(6,11,40,42,43$, 44, 54, 61, 70, 72, 81 e CP6108).

A prevalência é maior entre adolescentes e mulheres jovens, e a primeira infecção pelo HPV geralmente ocorre no início da atividade sexual ${ }^{3,4,8}$.

Durante a gravidez, as mulheres sofrem grandes alterações fisiológicas e imunológicas capazes de interferir na infecção pelo HPV ${ }^{9}$. Isso se faz perceptível em observações clínicas que indicam um aumento do número de mulheres com lesões condilomatosas, bem como lesões maiores em tamanho e quantidade no período gestacional ${ }^{10}$. $\bigcirc$ rastreio da infecção por HPV, durante a gestação, é importante por auxiliar na prevenção do aparecimento de condições associadas que favorecem complicações obstétricas, principalmente relacionadas à disfunção placentária ${ }^{1,12}$. Além dos aspectos maternos, há a preocupação da transmissão viral da mãe para o feto, sendo que dados epidemiológicos atuais demonstram que a transmissão vertical pode ocorrer antes, durante e depois do parto $^{13,14}$.

O estado do Maranhão apresenta uma das mais altas taxas de incidência de CCU estimadas para o Brasil, no ano de 2018, com 35,35 casos por 100.000 mulheres $^{15}$. Imperatriz é a segunda maior cidade em número de habitantes e em importância econômica do Maranhão ${ }^{16}$; apesar disso, não há estudos sobre a prevalência de infecção cervical por HPV na população feminina nem tampouco nas gestantes. As gestantes são suscetíveis à infecção pelo HPV, e a consequência de uma infecção não se restringe somente a um possível desenvolvimento de câncer no futuro, sendo potenciais transmissoras do HPV para seus bebês. Assim é importante para o planejamento em saúde pública que sejam realizados levantamentos das taxas de infecção pelo HPV em gestantes.

objetivo deste estudo foi determinar a prevalência da infecção pelo HPV em grávidas de Imperatriz, Maranhão.

\section{MATERIAIS E MÉTODOS}

Trata-se de um estudo observacional, descritivo e analítico, do tipo transversal, aprovado pelo Comitê de Ética em Pesquisa do Núcleo de Medicina Tropical da Universidade Federal do Pará (UFPA), sob parecer $n^{\circ} 031 / 2011$, em 28 de junho de 2011.

A amostra de conveniência foi composta de 167 grávidas selecionadas durante 0 atendimento no Hospital Regional Materno-Infantil de Imperatriz, maternidade pública de referência de Imperatriz, no ano de 2012. Foram incluídas gestantes com idade acima de 18 anos, com funções cognitivas preservadas no momento da coleta de dados e que concordaram em responder ao formulário de pesquisa por meio da assinatura do Termo de Consentimento Livre e Esclarecido. Foram excluídas aquelas com história de diabetes e hipertensão, sorologia positiva para HIV, fumantes, com distúrbio neurológico/convulsões e apresentando deficiência mental ou déficit cognitivo.

formulário clínico-epidemiológico abordou os seguintes tópicos: dados sociodemográficos e comportamentais, sexuais, anticoncepcionais, reprodutivos e ginecológicos. A coleta das informações foi realizada por entrevistador previamente treinado, para minimizar vieses, e antes da realização da consulta ginecológica.

Os procedimentos da colpocitologia foram realizados com a mulher em posição ginecológica, momento em que eram coletadas as amostras cervicais para colpocitologia e biologia molecular, por meio de raspado da mucosa cervical com escova estéril (kit para coleta de colpocitologia oncótica da Libbs $^{\circledR}$ ).

A pesquisa de HPV foi realizada no Laboratório de Imunopatologia do Núcleo de Medicina Tropical da UFPA. O DNA foi extraído das amostras com o kit GFX (GE Healthcare, Chicago, Ilinóis, EUA) e o DNA do HPV foi detectado por reação em cadeia da polimerase (PCR).

Inicialmente as amostras foram submetidas à $P C R$, usando-se primers para o gene da $\beta$-globina para certificar que o DNA extraído possuía qualidade adequada para as PCRs subsequentes.

Para detecção de DNA de HPV, foi realizada uma nested PCR, utilizando os primers MY09/MY11 e $\mathrm{GP5}+/ \mathrm{GP6}+{ }^{17,18}$. As reações de PCR foram realizadas 
em termociclador Eppendorf, utilizando GoTaq ${ }^{\circledR}$ Green Master Mix (Promega, Madison, Wisconsin, EUA). Para a primeira reação, utilizou-se $10 \mu \mathrm{L}$ de Mix, 8,2 de água e 0,8 $\mu \mathrm{L}$ de oligonucleotídeos MY09 e MY11 e 1,0 $\mu \mathrm{L}$ de DNA. A reação seguiu o seguinte protocolo: um ciclo de desnaturação inicial de $94{ }^{\circ} \mathrm{C}$ por $3 \mathrm{~min}$, 40 ciclos da amplificação de PCR, com desnaturação em $94{ }^{\circ} \mathrm{C}$ por $30 \mathrm{~s}$, anelamento a $56{ }^{\circ} \mathrm{C}$ por $30 \mathrm{~s}$ e extensão a $72{ }^{\circ} \mathrm{C}$ por $30 \mathrm{~s}$, extensão final a $72{ }^{\circ} \mathrm{C}$ por $5 \mathrm{~min}$, com reação mantida a $10^{\circ} \mathrm{C}$. A segunda reação ocorreu nas mesmas condições da anterior, sendo utilizados os primers GP5 e GP6, e a amostra de DNA foi de $1 \mu \mathrm{L}$ do produto da primeira reação.

Os produtos das reações foram submetidos à eletroforese em gel de agarose a 1,5\% em TBE. Os géis foram visualizados e fotografados em Genlianse da PerkinElmer (Waltham, EUA) pelo programa GeneSnap (Syngene), sendo consideradas positivas as reações que apresentaram uma banda de 440 pares de base (pb) para MY09/MY11 e banda de 150 pb para GP5+/GP6+. Em todas as reações da nested PCR, foram utilizados um controle positivo e outro negativo para DNA do HPV.

Os resultados obtidos foram armazenados em planilhas eletrônicas do programa Microsoft Excel 2010 (Microsoft Corp., EUA). A análise estatística foi realizada pelo programa Epi Info v3.5.1 (Centers for Disease Control and Prevention, Atlanta, EUA). Para a avaliação das hipóteses do estudo, foram realizados os testes qui-quadrado $\left(\chi^{2}\right)$, exato de Fisher e teste $G$, tendo nível alfa de significância de $5 \%$.

\section{RESULTADOS}

As características demográficas e epidemiológicas da amostra estudada estão representadas na tabela 1. A amostra foi composta por 167 gestantes, apresentando faixa etária média de 25,3 anos, variando de 18 a 44 anos de idade. O predomínio foi de solteiras, separadas ou viúvas. A maioria das participantes apresentou nível de escolaridade correspondente ao ensino médio completo ou superior incompleto.

Tabela 1 - Fatores de risco demográficos e epidemiológicos associados à infecção genital pelo HPV em gestantes da cidade de Imperatriz, estado do Maranhão, Brasil

\begin{tabular}{|c|c|c|c|c|c|c|}
\hline \multirow{2}{*}{ Variáveis } & \multicolumn{2}{|c|}{ Total } & \multicolumn{2}{|c|}{ DNA HPV } & \multirow{2}{*}{ OR } & \multirow{2}{*}{$p$} \\
\hline & $\mathrm{N}$ & $\%$ & $\mathrm{~N}$ & $\%$ & & \\
\hline \multicolumn{7}{|l|}{ Idade } \\
\hline 18 a 25 anos & 93 & 55,69 & 20 & 21,51 & \multirow{3}{*}{1,79} & \multirow{3}{*}{$0,1222^{*}$} \\
\hline 26 a 35 anos & 68 & 40,72 & 9 & 13,24 & & \\
\hline$>35$ anos & 6 & 3,59 & - & - & & \\
\hline \multicolumn{7}{|l|}{ Situação conjugal } \\
\hline Solteira/Separada/Viúva & 99 & 59,28 & 24 & 24,24 & \multirow{2}{*}{4,03} & \multirow{2}{*}{$0,0046^{t, \ddagger}$} \\
\hline Casada/União estável & 68 & 40,72 & 5 & 7,35 & & \\
\hline \multicolumn{7}{|l|}{ Nível de escolaridade } \\
\hline Analfabeta/Fund. incompleto & 39 & 23,36 & 4 & 10,26 & \multirow{2}{*}{\multicolumn{2}{|c|}{2,35}} \\
\hline Fund. completo/Médio incompleto & 33 & 19,76 & 7 & 21,21 & & \\
\hline Médio completo/Superior incompleto & 89 & 53,29 & 17 & 19,10 & 2,06 & \multirow[t]{2}{*}{$0,5578^{*}$} \\
\hline Superior completo & 6 & 3,59 & 1 & 16,67 & 1,75 & \\
\hline \multicolumn{7}{|l|}{ Idade da coitarca } \\
\hline$\leq 14$ anos & 29 & 17,37 & 6 & 20,69 & \multirow{2}{*}{1,30} & \multirow{2}{*}{$0,5950^{\dagger}$} \\
\hline$>14$ anos & 138 & 82,63 & 23 & 16,67 & & \\
\hline \multicolumn{7}{|l|}{ Parceiros sexuais na vida } \\
\hline 1 parceiro & 45 & 26,95 & 6 & 13,33 & \multirow{3}{*}{$\begin{array}{l}1,40 \\
1,69\end{array}$} & \\
\hline 2 a 3 parceiros & 64 & 38,32 & 11 & 17,19 & & \multirow{2}{*}{$0,6194^{+}$} \\
\hline$\geq 4$ parceiros & 58 & 34,73 & 12 & 20,69 & & \\
\hline \multicolumn{7}{|l|}{ Parceiros sexuais no último ano } \\
\hline$\leq 1$ parceiro & 150 & 89,82 & 23 & 15,33 & \multirow{2}{*}{3,01} & \multirow{2}{*}{$0,0794^{\dagger}$} \\
\hline$\geq 2$ parceiros & 17 & 10,18 & 6 & 35,29 & & \\
\hline \multicolumn{7}{|l|}{ Parceiro sexuais novos no último ano } \\
\hline Nenhum & 163 & 97,60 & 28 & 17,18 & \multirow{2}{*}{1,60} & \multirow{2}{*}{$0,9831^{\dagger}$} \\
\hline$\geq 1$ parceiro & 4 & 2,40 & 1 & 25,00 & & \\
\hline
\end{tabular}

OR: Odds ratio; Sinal convencional utilizado: - Dado numérico igual a zero, não resultante de arredondamento; ${ }^{*}$ Teste $G ;{ }^{\dagger}$ Teste do qui-quadrado ou exato de Fisher; ${ }^{\ddagger} p \leq 0,05$. 
Em mais de $80 \%$ das entrevistadas, a primeira relação sexual ocorreu depois dos 14 anos de idade, com média de 16,9 anos. As características comportamentais das gestantes estudadas estão expressas na tabela 2 .

Quando foi analisada a variável história anticoncepcional e reprodutiva, verificou-se que todas as mulheres $(167 ; 100,00 \%)$ já utilizaram ou utilizam anticoncepcional hormonal oral. Em relação ao uso de camisinha, apenas $53(31,74 \%)$ das grávidas relataram usá-la durante o ato sexual. Do total da amostra, 62 $(37,13 \%)$ tiveram apenas uma gestação.

Quanto à história ginecológica, 158 (94,61\%) das gestantes relataram não apresentar qualquer tipo de doença sexualmente transmissível (DST). Todas as participantes do estudo tiveram corrimento ou irritação vaginal em algum momento da vida. A maioria das pacientes $(119 ; 71,26 \%)$ já havia realizado o exame preventivo do câncer de colo do útero (PCCU) mais de uma vez na vida.

A prevalência da infecção genital pelo HPV em gestante, em Imperatriz, foi de 17,36\% (29). Aquelas com idade entre 18 a 25 anos apresentaram a maior prevalência da infecção pelo HPV, correspondendo a $21,51 \%$ (20), decrescendo conforme o aumento da idade (Tabela 1).

A respeito do estado conjugal (Tabela 1), verificou-se que as gestantes solteiras/separadas/viúvas (24; 24,24\%) apresentaram maior chance de adquirir a infecção pelo HPV em relação às casadas (5; 7,35\%), com resultados estatisticamente significantes $(\mathrm{OR}=4,03 ; p=0,0046)$.

Quanto ao grau de instrução, verificou-se que não houve significância estatística entre os grupos analisados (Tabela 1).

Quando analisado o comportamento sexual relativo à infecção pelo HPV, os resultados não mostraram significância estatística; entretanto, alguns dados despertaram a atenção. Gestantes que tiveram coitarca com idade igual ou inferior a 14 anos apresentaram maior prevalência da infecção pelo HPV em relação àquelas com coitarca após 14 anos. A predominância do HPV foi maior proporcionalmente ao aumento do número de parceiros tanto no decorrer da vida, no último ano ou em novos parceiros no último ano (Tabela 1).

Tabela 2 - Fatores de riscos comportamentais associados à infecção genital pelo HPV em gestantes da cidade de Imperatriz, estado do Maranhão, Brasil

\begin{tabular}{|c|c|c|c|c|c|c|}
\hline \multirow{2}{*}{ Variáveis } & \multicolumn{2}{|c|}{ Total } & \multicolumn{2}{|c|}{ DNA HPV } & \multirow{2}{*}{ OR } & \multirow{2}{*}{$p$} \\
\hline & N & $\%$ & $\mathrm{~N}$ & $\%$ & & \\
\hline \multicolumn{7}{|l|}{ Uso de pílula } \\
\hline Sim & 167 & 100 & 29 & 17,37 & - & $1,00^{*}$ \\
\hline Não & - & - & - & & & \\
\hline \multicolumn{7}{|l|}{ Uso de camisinha } \\
\hline Sim & 53 & 31,74 & 10 & 18,87 & \multirow{2}{*}{0,86} & \multirow{2}{*}{$0,8267^{*}$} \\
\hline Não & 114 & 68,26 & 19 & 16,67 & & \\
\hline \multicolumn{7}{|c|}{ Frequência do uso de camisinha } \\
\hline Nunca & 114 & 68,26 & 19 & 16,67 & \multirow{3}{*}{-} & \multirow{3}{*}{$0,7621^{\dagger}$} \\
\hline Às vezes & 52 & 31,14 & 10 & 19,23 & & \\
\hline Sempre & 1 & 0,60 & - & - & & \\
\hline \multicolumn{7}{|l|}{ Gravidez } \\
\hline 1 gestação & 62 & 37,13 & 18 & 29,03 & \multirow{2}{*}{3,42} & \multirow{2}{*}{$0,0032^{*}, \neq$} \\
\hline$\geq 2$ gestações & 105 & 62,87 & 11 & 10,48 & & \\
\hline \multicolumn{7}{|l|}{ História de DST } \\
\hline $\operatorname{Sim}$ & 9 & 5,39 & 1 & 11,11 & \multirow{2}{*}{0,58} & \multirow{2}{*}{$0,5914^{*}$} \\
\hline Não & 158 & 94,61 & 28 & 17,72 & & \\
\hline \multicolumn{7}{|c|}{ Corrimento/Irritação vaginal } \\
\hline $\operatorname{Sim}$ & 167 & 100 & 29 & 17,37 & \multirow[t]{2}{*}{-} & \multirow{2}{*}{$1,00^{*}$} \\
\hline Não & - & - & - & - & & \\
\hline \multicolumn{7}{|l|}{ Frequência de PCCU } \\
\hline Este é o primeiro & 48 & 28,74 & 12 & 25,00 & \multirow{2}{*}{2,00} & \multirow{2}{*}{$0,1171^{*}$} \\
\hline Outros & 119 & 71,26 & 17 & 14,29 & & \\
\hline
\end{tabular}

DST: Doenças sexualmente transmissíveis; PCCU: Preventivo do câncer de colo do útero; OR: Odds ratio; Sinal convencional utilizado: - Dado numérico igual a zero, não resultante de arredondamento; ${ }^{*}$ Teste do qui-quadrado ou exato de Fisher; ${ }^{\dagger}$ Teste $G ;{ }^{\ddagger} p \leq 0,05$. 
Verificou-se maior prevalência (18,87\%) da infecção pelo HPV em mulheres que faziam uso de preservativo; porém, não houve diferença estatisticamente significante em relação as que não usavam. As gestantes que se declararam primigestas apresentaram maior prevalência da infecção pelo HPV (29,03\%), achado relevante ( $p=0,001)$, com 3,42 vezes mais chances de adquirir a infecção pelo HPV, em relação às mulheres que já engravidaram duas ou mais vezes (Tabela 1).

Em relação ao histórico de DST, as mulheres que manifestaram maior prevalência do HPV foram as que relataram ausência anterior das mesmas. Aquelas que estavam realizando o primeiro PCCU, na ocasião do estudo, apresentaram maior prevalência da infecção pelo HPV $(25,00 \%)$ em relação àquelas que já haviam realizado esse exame anteriormente (14,29\%), não sendo estatisticamente significativo (Tabela 1).

\section{DISCUSSÃO}

A infecção genital pelo HPV é um grande problema de saúde pública, principalmente por sua estreita relação com o desenvolvimento do CCU. Essa infecção merece atenção redobrada durante a gravidez, por ser um período no qual ocorre alteração da imunidade e modificação dos hormônios esteroides, predispondo a mulher a infecções por vírus ${ }^{10}$.

Ainda que a infecção da cérvice uterina pelo HPV possa se manter quiescente e as mulheres possam gerar embriões saudáveis, é importante acompanhar essas gestantes com atenção, pois há maior risco de ruptura prematura de bolsa e aborto, além do risco de transmissão do vírus para o bebê $\hat{e}^{19}$.

A prevalência da infecção pelo HPV em gestantes, no Hospital Regional Materno-Infantil de Imperatriz, foi de 17,36\%. Há poucos estudos de prevalência de HPV em gestantes saudáveis no Brasil; um deles, feito na Região Sul, reportou uma prevalência mais elevada $(25,3 \%)^{20}$ que a encontrada no presente estudo. Mundialmente os dados variam, mas num estudo de meta-análise que incluiu 28 trabalhos com gestantes da América do Norte, Ásia e Europa, foi registrada uma prevalência $(16,82 \%)^{21}$ semelhante à encontrada no presente estudo.

A idade é um dos fatores mais relevantes que afeta a prevalência da infecção pelo HPV em mulheres grávidas ou não 22 . No presente estudo, a maior prevalência ocorreu na faixa etária de 18 a 25 anos, decaindo com o aumento da idade. Esse resultado é condizente com a literatura, que demonstra maior risco de infecção pelo HPV em gestantes jovens ( $<25$ anos de idade $)^{21}$. É possível que o tal aumento, nessa faixa etária, esteja relacionado à exposição precoce da zona de transformação cervical aos agentes sexualmente transmissíveis. Isso é particularmente preocupante, pois, nessa idade, a junção escamo-colunar está em alta atividade mitótica e metaplásica e, ao mesmo tempo, imatura; portanto suscetível a agressões oncogênicas, facilitando o surgimento de neoplasias intraepiteliais associadas ao HPV23,24.
As gestantes solteiras apresentaram maior risco de adquirir a infecção pelo HPV do que as casadas $(O R=4,03 ; p=0,0046)$, o que pode ser explicado pela possibilidade das mulheres solteiras possuírem maior número de parceiros do que as mulheres em uniões estáveis, fato que aumenta as chances de contaminação pelo HPV. Assim, os resultados deste estudo indicam que a monogamia está relacionada à proteção contra a infecção de maneira semelhante ao que foi observado anteriormente ${ }^{25}$.

Apesar da iniciação sexual antes dos 18 anos de idade ser considerada precoce, devido à cérvice ainda não estar completamente formada nem os níveis hormonais estabilizados, não é raro que ocorra entre 15 e 18 anos de idade ${ }^{26}$. As gestantes entrevistadas tiveram uma iniciação sexual precoce, predominando a faixa etária dos 14 aos 20 anos (Tabela 1). A infecção por HPV foi maior entre as gestantes que iniciaram a vida sexual antes dos 14 anos de idade, porém não foi estatisticamente significante. Na literatura, estudos com grávidas e não grávidas mostraram que aquelas que realizaram coitarca em idade precoce apresentavam maiores chances de se infectar com o HPV ${ }^{14,27}$, indicando que a idade da iniciação sexual é relevante para a infecção por HPV, tanto em gestantes, quanto não gestantes.

Apesar de não ser estatisticamente significante, quanto maior o número de parceiros na vida, maior foi a prevalências do HPV, tendência que se repetiu em "número de parceiros no último ano" e "número de parceiros novos no último ano" (Tabela 1). $O$ número de parceiros, durante a vida sexual, foi relacionado à probabilidade de desenvolvimento de alterações intraepiteliais, uma vez que quanto maior o número de parceiros sexuais maior a chance de contrair DST, dentre elas o HPV24,28,29.

Segundo o relato das mulheres entrevistadas neste trabalho, o preservativo não foi utilizado nas relações sexuais, ou pelo menos não constantemente, e seu uso não foi relacionado estatisticamente com a infecção por HPV. Mas, verifica-se que, em sua maioria, as mulheres que disseram usar preservativo não o faziam em todas as relações, sendo assim, estavam mais expostas à infecção pelo HPV. Dessa forma, mais uma vez, os dados sugerem que a prevenção de DST mais viável, incluindo o HPV, ainda é o uso do preservativo em todas as relações sexuais, mesmo em relações estáveis com um único parceiro ${ }^{30}$.

Todas as gestantes utilizaram anticoncepcional oral alguma vez na vida. A relação entre o risco de infecção por HPV e o uso prolongado de contraceptivos orais ainda é controverso ${ }^{31,32}$. Independentemente da relação direta entre os anticoncepcionais orais e infecção por HPV, é necessário levar em consideração que mulheres em relações estáveis ou não, que utilizam esse método contraceptivo, têm menor tendência a utilizar preservativos, facilitando assim a entrada de DST ${ }^{33,34}$.

As DST são um sério fator de risco para lesões da cérvice uterina e consequentemente infecção por HPV. A maioria das mulheres participantes deste estudo 
informou que nunca contraiu alguma DST. Essa informação deve ser vista com cautela, uma vez que muitas pacientes, apesar de perceberem os sintomas, não procuram diagnóstico e/ou tratamento adequado, pois essas doenças são circundadas por forte preconceito social associado à vergonha de quem tem o diagnóstico positivo 35,36

Estudos epidemiológicos apontam o maior número de gestações como um fator de risco associado à infecção por HPV37,38. Na presente pesquisa, observou-se que, com o aumento da paridade, houve redução da prevalência de infecção pelo HPV. As primigestas apresentaram maior prevalência da infecção pelo HPV $(29,03 \%)$ em relação às que tiveram duas ou mais gestações, sendo estatisticamente significante $(p=0,001)$. A maior prevalência de HPV entre as primigestas pode ser explicada pelo fato da população deste estudo ser constituída somente por mulheres grávidas. A maioria dos estudos analisa apenas mulheres não grávidas e suas chances de contaminação por HPV associado ao número de gestações passadas. Assim sendo, com esses resultados é possível especular que as primigestas sejam mais suscetíveis à infecção por HPV do que mulheres em suas subsequentes gestações. Além disso, é preciso observar que a população em estudo era constituída por mais de $50 \%$ de mulheres mais jovens que 25 anos de idade, e mais de $90 \%$ eram mais jovens que 35 anos de idade, portanto, dentro da faixa etária de maior risco para infecção por HPV e, aproximadamente $60 \%$ das gestantes eram solteiras, sendo esses fatores de risco associados à infecção por HPV neste estudo.

\section{CONCLUSÃO}

Foi encontrada uma alta prevalência de infecção pelo HPV no grupo estudado. As características dessa população e os fatores de risco avaliados permitiram concluir que as gestantes mais suscetíveis à infecção pelo HPV são mulheres jovens, que estão grávidas pela primeira vez e estão em relações conjugais não estáveis. Esses resultados sugerem a necessidade de se combater a infecção pelo HPV por meio da implantação ou ampliação de programas de educação sexual, prevenção e planejamento familiar voltados, prioritariamente, ao público jovem. Também devem ser ampliados os programas continuados de vacinação contra o HPV, a fim de minimizar infecções genitais e sua persistência, prevenindo o surgimento, em alguns anos, do câncer de colo de útero nessas mulheres. Além disso, alertam que é necessário o acompanhamento pré-natal vigilante para os sintomas e para o tratamento da infecção por HPV nessa população.

\section{CONFLITOS DE INTERESSE}

Os autores declaram que não houve conflito de interesses.

\section{CONTRIBUIÇÃO DOS AUTORES}

Todos os autores contribuíram com a idealização do estudo, a análise e a interpretação dos dados e com a redação do manuscrito, aprovando a versão final publicada. Declaram-se responsáveis pelo conteúdo integral do artigo, garantindo sua precisão e integridade.

\section{REFERÊNCIAS}

1 Organização das Nações Unidas. OMS: 85\% das mortes por câncer de colo de útero ocorrem em países de média e baixa renda [Internet]. Brasília: ONU; 2017 fev [citado 2018 set 24]. Disponível em: https://nacoesunidas.org/oms-85-das-mor tes-por-cancer-de-colo-de-utero-ocorrem-em-p aises-de-media-e-baixa-renda/.

2 Instituto Nacional de Câncer (BR). Estimativa 2018: incidência de câncer no Brasil. Síntese de resultados e comentários [Internet]. Rio de Janeiro: INCA; 2017 [citado 2018 set 17]. Disponível em: http://www.inca.gov.br/estimativa/2018/sintese-de-r esultados-comentarios.asp.

3 Ayres ARG, Silva GA. Cervical HPV infection in Brazil: systematic review. Rev Saude Publica. 2010 Oct;44(5):963-74.

4 Moody CA, Laimins LA. Human papillomavirus oncoproteins: pathways to transformation. Nat Rev Cancer. 2010;10:550-60.

5 Rosa MI, Medeiros LR, Rosa DD, Bozzeti MC, Silva FR, Silva BR. Papilomavírus humano e neoplasia cervical. Cad Saude Publica. 2009 mai;25(5):953-64.
6 Sasagawa T, Takagi H, Makinoda S. Immune responses against human papillomavirus (HPV) infection and evasion of host defense in cervical cancer. J Infect Chemother. 2012;18(6): 807-15.

7 Muñoz N, Bosch FX, Sanjosé S, Herrero R, Castellsagué $X$, Shah KV, et al. Epidemiologic classification of human papillomavirus types associated with cervical cancer. $N$ Engl J Med. 2003 Feb;348(6):518-27.

8 Zheng ZM, Baker CC. Papillomavirus genome structure, expression, and post-transcriptional regulation. Front Biosci. 2006;1 1:2286-302.

9 Mor G, Cardenas I. The immune system in pregnancy: a unique complexity. Am J Reprod Immunol. 2010 May;63(6):425-33.

10 Singhal P, Naswa S, Marfatia YS. Pregnancy and sexually transmitted viral infections. Indian J Sex Transm Dis AIDS. 2009 Jul-Dec;30(2):71-8.

11 Kwon JY, Romero R, Mor G. New insights into the relationship between viral infection and pregnancy complications. Am J Reprod Immunol. 2014 May;71 (5):387-90. 
12 Cho G, Min KJ, Hong HR, Kim S, Hong JH, Lee JK, et al. High-risk human papillomavirus infection is associated with premature rupture of membranes. BMC Pregnancy Childbirth. 2013 Sep;13:173.

13 Skoczyński M, Goździcka-Józefiak A, Kwaśniewska A. The prevalence of human papillomavirus between the neonates and their mothers. BioMed Res Int. 2015;2015:126417.

14 Castellsagué X, Drudis T, Cañadas MP, Goncé A, Ros R, Pérez JM, et al. Human papillomavirus (HPV) infection in pregnant women and mother-to-child transmission of genital HPV genotypes: a prospective study in Spain. BMC Infect Dis. 2009;9:74.

15 Instituto Nacional de Câncer (BR). Estimativa 2018: incidência de câncer no Brasil: neoplasia maligna da mama feminina e colo do útero [Internet]. Rio de Janeiro: INCA; 2017 [citado 2018 abr 24]. Disponível em: http://www.inca.gov.br/ estimativa/2018/mapa-mama-feminina-colo-utero. asp.

16 Instituto Brasileiro de Geografia e Estatística. Produto interno bruto dos municípios: Brasil / Maranhão / Imperatriz [Internet]. Rio de Janeiro: IBGE; 2010 [citado 2018 abr 24]. Disponível em: https://cidades.ibge.gov.br/brasil/ma/imperatriz/ quisa $/ 38 / 47001$ ?tipo $=$ ranking\&indicador $=47007$.

17 Gravitt PE, Peyton CL, Alessi TQ, Wheeler $C M$, Coutlée F, Hildesheim A, et al. Improved amplification of genital human papillomaviruses. J Clin Microbiol. 2000 Jan;38(1):357-61

18 Venceslau EM, Bezerra MM, Lopes ACM, Souza EV, Onofre ASC, Melo CM, et al. HPV detection using primers MY09/ MY1 1 and GP5+/GP6+ in patients with cytologic and/or colposcopic changes. J Bras Patol Med Lab. 2014 Jul-Aug;50(4):280-5.

19 Souho T, Benlemlih M, Bennani B. Human papillomavirus infection and fertility alteration: a systematic review. PLoS One. 2015 May; 10(5):e0126936.

20 Salcedo MMBP, Damin APS, Agnes G, Pessini SA, El Beitune P, Alexandre COP, et al. Prevalence of human papillomavirus infection in pregnant versus non-pregnant women in Brazil. Arch Gynecol Obstet. 2015 Dec;292(6):1273-8.

21 Liu $P, X_{u} L$, Sun $Y$, Wang Z. The prevalence and risk of human papillomavirus infection in pregnant women. Epidemiol Infect. 2014 Aug;142(8): 1567-78.

22 Bruni L, Diaz M, Castellsagué X, Ferrer E, Bosch FX, Sanjosé S. Cervical human papillomavirus prevalence in 5 continents: meta-analysis of 1 million women with normal cytological findings. J Infect Dis. 2010 Dec;202(12): 1789-99.

23 Moscicki AB. Impact of HPV infection in adolescent populations. J Adolesc Health. 2005 Dec;37/6 Suppl):S3-9.
24 Nonnenmacher B, Breitenbach V, Villa LL, Prolla JC, Bozzetti MC. Identificação do papilomavírus humano por biologia molecular em mulheres assintomáticas. Rev Saude Publica. 2002 fev;36(1):95-100.

25 Rama CH, Roteli-Martins CM, Derchain SFM, Longatto-Filho A, Gontijo RC, Sarian LOZ, et al. Prevalência do HPV em mulheres rastreadas para o câncer cervical. Rev Saude Publica. 2008 fev;42(1):123-30.

26 Martins LBM, Costa-Paiva LHS, Osis MJD, Sousa $\mathrm{MH}$, Pinto-Neto AM, Tadini V. Fatores associados ao uso de preservativo masculino e ao conhecimento sobre DST/AIDS em adolescentes de escolas públicas e privadas do Município de São Paulo, Brasil. Cad Saude Publica. 2006 fev;22(2):315-23.

27 Roteli-Martins CM, Longatto Filho A, Hammes LS, Derchain SFM, Naud P, Matos JC, et al. Associação entre idade ao início da atividade sexual e subseqüente infecção por papilomavírus humano: resultados de um programa de rastreamento brasileiro. Rev Bras Ginecol Obstet. 2007 nov;29(1 1):580-7.

28 Carret MLV, Fassa AG, Silveira DS, Bertoldi AD, Hallal PC. Sintomas de doenças sexualmente transmissíveis em adultos: prevalência e fatores de risco. Rev Saude Publica. 2004 fev;38(1):76-84.

29 Moscicki AB. Human papillomavirus infection in adolescents. Pediatr Clin North Am. 1999 Aug;46(4):783-807.

30 Hogewoning CJA, Bleeker MCG, van den Brule AJC, Voorhorst FJ, Snijders PJF, Berkhof J, et al. Condom use promotes regression of cervical intraepithelial neoplasia and clearance of human papillomavirus: a randomized clinical trial. Int J Cancer. 2003 Dec;107(5):811-6.

31 Baudu A, Prétet JL, Riethmuller D, Chotard M, Mougin C, Mercier M. Prevalence and risk factors of human papillomavirus infection types 16/18/45 in a cohort of French females aged 15-23 years. J Epidemiol Glob Health. 2014 Mar;4(1):35-43.

32 Syriänen K, Shabalova I, Petrovichev N, Kozachenko V, Zakharova T, Pajanidi J, et al. Oral contraceptives are not an independent risk factor for cervical intraepithelial neoplasia or high-risk human papillomavirus infections. Anticancer Res. 2006 Nov-Dec;26(6C):4729-40.

33 Carrasco-Garrido P, López de Andrés A, Hernández Barrera V, Jiménez-Trujillo I, Santos-Sancho J, Jiménez-García R. Predictors of contraceptive methods among adolescents and young women residing in Spain. J Sex Med. 2011 Sep;8(9):2431-8.

34 Eisenberg DL, Allsworth JE, Zhao Q, Peipert JF. Correlates of dual-method contraceptive use: an analysis of the National Survey Of Family Growth (2006-2008). Infect Dis Obstet Gynecol. 2012 Feb;2012:717163. 
35 Fortenberry JD, McFarlane M, Bleakley A, Bull S, Fishbein M, Grimley DM, et al. Relationships of stigma and shame to gonorrhea and HIV screening. Am J Public Health. 2002 Mar;92(3):378-81.

36 Newton-Levinson A, Leichliter JS, Chandra-Mouli V. Sexually transmitted infection services for adolescents and youth in low- and middle-income countries: perceived and experienced barriers to accessing care. J Adolesc Health. 2016 Jul;59(1):7-16.
37 Bosch FX, Sanjosé S. The epidemiology of human papillomavirus infection and cervical cancer. Dis Markers. 2007;23(4):213-27.

38 Vinodhini K, Shanmughapriya S, Das BC, Natarajaseenivasan K. Prevalence and risk factors of HPV infection among women from various provinces of the world. Arch Gynecol Obstet. 2012 Mar;285(3):771-7. 